\title{
Self-Adaptive Firefly-Algorithm-Based Unified Power Flow Controller Placement with Single Objectives
}

\author{
Selvarasu Ranganathan ${ }^{1}$ and S. Rajkumar $\mathbb{D}^{2}$ \\ ${ }^{1}$ Department of Electrical Engineering, School of Electrical Engineering and Computing, \\ Adama Science and Technology University (ASTU), Adama, Ethiopia \\ ${ }^{2}$ Department of Electronics and Communication Engineering, School of Electrical Engineering and Computing, \\ Adama Science and Technology University (ASTU), Adama, Ethiopia \\ Correspondence should be addressed to S. Rajkumar; rajkumar.sriramulu@astu.edu.et
}

Received 4 February 2021; Revised 29 June 2021; Accepted 22 July 2021; Published 31 July 2021

Academic Editor: Saleh Mobayen

Copyright (c) 2021 Selvarasu Ranganathan and S. Rajkumar. This is an open access article distributed under the Creative Commons Attribution License, which permits unrestricted use, distribution, and reproduction in any medium, provided the original work is properly cited.

\begin{abstract}
The selection of positions for unified power flow controller (UPFC) placement in transmission network is an essential factor, which aids in operating the system in a more reliable and secured manner. This paper focuses on strengthening the power system performance through UPFC placement employing self-adaptive firefly algorithm (SAFA), which selects the best positions along with parameters for UPFC placement. Three single objectives of real power loss reduction, voltage profile improvement, and voltage stability enhancement are considered in this work. IEEE 14, 30, and 57 test systems are selected to accomplish the simulations and to reveal the efficacy of the proposed SAFA approach; besides, solutions are compared with two other algorithms solutions of honey bee algorithm (HBA) and bacterial foraging algorithm (BFA). The proposed SAFA contributes real power loss reduction, voltage profile improvement, and voltage stability enhancement by optimally choosing the placement for UPFC.
\end{abstract}

\section{Introduction}

Power system stability is the most challenging for power system engineers due to the ever increasing load demand; as a result, the power system network falls to stressed condition, which leads to loss reduction and voltage instability. Moreover, it is a challenge to widen the existing network to satisfy the growing power demand by setting up new generation and transmission networks owing to economic and environmental constraints. Installation of flexible alternating transmission system (FACTs) controllers in transmission network is a possible solution to overcome the stability issues.

FACTs controller is classified into series, shunt and blending of series and shunt controller. Static var compensator (SVC) belongs to shunt controller, thyristor controlled series compensator (TCSC) comes under series controller, and UPFC associates with a combination of series and shunt controller. UPFC has the capability to serve as a series and shunt controller simultaneously; thereby, it controls the power flow, bus voltages, and phase angle with altering transmission line impedance [1-3].

Power system researchers have been paying their attention to carry out their research on optimal FACTs placement in transmission network for the last three decades to strengthen the existing power system performance. Nonconventional optimization algorithms of GA, DE, PSO, Honey Bees Algorithm (HBA), Ant Colony Optimization (ACO), Bacterial Foraging Algorithm (BFA), Firefly Algorithm (FA), Whale Optimization Algorithm (WOA), and Gravitational Search Algorithm (GSA) are commonly employed to solve power system optimization problems as they offer high-quality solutions [4-24].

Power system available transfer capability has been improved by the FACTs placement using HBA [4]. Evolutionary algorithms have been proposed to select the feasible locations and parameters of TCSC for increase of the power flow, reduction of losses, and enhancement of stability of the 
system, and also performances are tested in IEEE 14 bus system [5]. A fuzzy lag-lead controller has been used to control the parameters of TCSC and SVC for oscillation damping, stability enhancement, and ant colony optimization algorithm applied for setting of parameters of TCSC and SVC [6].

Particle swarm optimization was employed to improve power transfer capability and economic power system operation through proper SVC and TCSC placement [7]. A complete review of application of particle swarm optimization for FACTs placement in power system network has been reported [8]. A new Honey Bee Algorithm (HBA) has been proposed to overcome the limitation of conventional HBA, which offers near optimum solution for economic dispatch problem. The proposed algorithm improves matting process by combining chaotic local search, which has been applied in order to solve economic dispatch problem [9].

Bacterial foraging algorithm (BFA) has been applied to solve optimization problem more than it has been employed for minimizing loss and enhancing voltage profile through UPFC placement [10]. BFA has been employed for capacitor placement in radial distribution system in which BFA determines the optimal locations and size for capacitor placement in order to improve the performance of the system in terms of reducing power loss and improving voltage profile [11]. Dr. Yang developed firefly algorithm (FA) for solving optimization problem [12]. The FA has been attracting power system researchers for solving power system optimization problems of economic dispatch and unit commitment $[13,14]$.

The limitation of FA includes slow process, lower convergence rate, and offering suboptimal solution. In order to overcome the limitations of FA, SAFA has been applied for placement of SVC, UPFC, and TCSC. The research work has addressed only one objective of loss minimization through SVC, UPFC, and TCSC placement [15-17]. Consequently, the author has considered multiobjectives for FACTs placement using SAFA in which SVC, TCSC, and UPFC have been chosen as FACTs devices for their placement to strengthen the power system performance by loss reduction, VP improvement, and VS enhancement [1].

The shunt-connected FACTs devices of SVC and STATCOM have been considered to compare their operating characteristics, and the solutions reveal that STATCOM provides better advantages than SVC [18]. The whale optimization algorithm has been proposed for SVC and TCSC placement in IEEE 30 and 57 test systems. They reported objectives of loss reduction and voltage profile improvement through shunt- and series-connected FACTs devices placement. In addition, WOA has been used for designing multi-input single-output controller of SSSC for stability enhancement $[19,20]$.

An evolutionary algorithm of teaching-learning-based optimization was addressed for loss reduction, cost minimization, and voltage deviation reduction through TCSC placement. However, the author failed to address the way of selecting the number of TCSC for their placement [21]. A gravitational search algorithm has been presented for TCSC placement for controlling congestion management in deregulated environment and analysed by considering normal and contingency conditions [22].

Ant colony optimization has been proposed for tuning the gain parameters of PI controller, which has been used to control the gate signal of SSSC in order to damp oscillations and deviations in voltage of multimachine power system. Subsequently multimachine system stability has been enhanced by the application of ACO [23]. Artificial bee colony algorithm has been presented for solving reactive power dispatch problem aiming at loss minimization and voltage stability enhancement [24].

UPFC has been considered to improve the transmission capacity by optimal placement and the solutions are presented with comparisons [25]. An updated complete review has been presented for multitype FACTs devices placement and different metaheuristic techniques employed for their placement [26]. Artificial neural network has been applied for monitoring online voltage of power system. In addition voltage stability enhancement and loadability have been increased by optimally placing FACTs devices in IEEE 14 bus system [25-34].

In recent years, the FACTS devices attract the system engineers and researchers for providing better adaptation to varying operational conditions and improving the usage of existing installations. The placement of FACTS devices can be described as an optimization problem with the objective of minimizing the network loss. Based on the above findings, the researchers failed to concentrate on the placement of UPFC with different single objectives.

There is thus a need for developing better strategies for optimally selecting the parameters with a view of obtaining the global best solution besides achieving better convergence. So, in this work, Self-Adaptive-FA- (SAFA-) based strategies have been proposed to minimize the transmission loss through placing TCSCs [14] and UPFCs effectively.

Thus, our work provides the following:

(i) Real power loss reduction

(ii) Voltage profile improvement

(iii) Voltage stability improvement

(iv) A strategy of new SAFA employed to identify feasible positions for UPFC placement

(v) Three IEEE 14, 30, and 57 bus systems considered

(vi) Simulated results are compared with other two metaheuristic optimization algorithm solutions

(vii) The self-adaptive scheme attempts to prevent suboptimal solution and enhance the convergence of the algorithm

\section{Firefly Algorithm}

It is a firefly-based metaheuristic optimization algorithm for solving power system optimization problem [12]. The light intensity of two fireflies' $r$ and $s$ decides the movement of attraction of two fireflies.

Light intensity (LI) of rth firefly is represented by vector $\left(X_{r}\right)$ as in 


$$
\operatorname{LI}_{r}=\operatorname{Fitness}\left(x_{r}\right)=\left[x_{r}^{1}, x_{r}^{2}, \ldots, x_{r}^{\mathrm{nd}}\right] .
$$

The attractiveness parameter between two fireflies of $r$ and $s$ is represented as

$$
\beta_{r, s}=\left(\beta_{\max , r, s}-\beta_{\min , r, s}\right) \exp \left(-\gamma_{r} r_{r, s}^{2}\right) .
$$

The Cartesian distance between fireflies' $r$ and $s$ is as follows:

$$
r_{r, s}=\left\|x_{r}-x_{s}\right\|=\sqrt{\sum_{v=1}^{\text {nd }}\left(x_{r}^{m}-x_{s}^{m}\right)^{2}}
$$

Firefly position is being updated at the end of each iterative step by their movement towards brighter firefly. The movement of firefly " $r$ " towards firefly " $s$ " at $m^{\text {th }}$ iteration is presented in

$$
\begin{aligned}
& x_{r}(m)=x_{r}(m-1)+ \\
& \quad \beta_{r, s}\left(x_{s}(m-1)-x_{r}(m-1)\right)+\alpha(\text { rand }-0.5) .
\end{aligned}
$$

2.1. Self-Adaptive Firefly Algorithm (SAFA). In SAFA, individual firefly decision variables include firefly parameters such as random movement factor $(\alpha)$, attractiveness parameter $\left(\beta_{\min }\right)$, and absorption coefficient $(\gamma)$. In previous studies, the researchers have used firefly algorithm for placement of FACTs devices. In firefly algorithm, the firefly parameters are fixed. The firefly parameters need to be tuned manually to obtain feasible solutions after each iteration. In this proposed SAFA, the parameters are tuned by selfadaptive mechanism in each iterative step by inclusion of three parameters namely $\alpha_{r}, \beta_{\min , r}, \gamma$ with the number of decision variables of representation of firefly equation (1) and the firefly is represented as

$$
x_{r}=\left[x_{r}^{1}, x_{r}^{2}, \ldots, x_{r}^{\mathrm{nd}}, \alpha_{r}, \beta_{\min , r}, \gamma_{r}\right]
$$

Each firefly with their parameters undergoes a whole search process; however, (2) is modified based on the brightness of fireflies as follows:

$$
\beta_{r, s}=\left(\beta_{\max , r, s}-\beta_{\min , r, s}\right) \exp \left(-\gamma_{r} r_{r, s}^{2}\right)+\beta_{\min , r, s} .
$$

The advantage of SAFA includes less computational effort, avoiding the suboptimal solution and convergence enhancement.

\section{Mathematical Modelling of UPFC}

Real and reactive power flow between the buses $i$ and $j$ are represented by [1]

$$
\text { Real power, } P_{i j}=\frac{V_{i} V_{j}}{x_{i j}} \sin \delta_{i j} \text {, }
$$

Reactive Power, $Q_{i j}=\frac{1}{x_{i j}}\left(V_{i}^{2}-V_{i} V_{j} \cos \delta_{i j}\right)$.
UPFC is modelled by combining series and shunt FACTs controllers. TCSC belongs to series controller, and its reactance $\left(X_{\mathrm{tc}}\right)$ is decided by the compensation factor and transmission line reactance $\left(X_{\text {line }}\right)$ in which they are connected. The modelling of TCSC is formed by its reactance and is presented as

$$
\begin{aligned}
& X_{\mathrm{tc}}=\gamma_{\mathrm{tc}} X_{\text {line }}, \\
& X_{i j}=X_{\text {line }}+X_{\mathrm{tc}} .
\end{aligned}
$$

SVC is one of the shunt controllers and is used to modify/control bus voltages through reactive power generation/absorption. SVC alter the reactive power $\left(\Delta Q_{i}\right)$ of the bus at which they are connected as follows:

$$
\Delta Q_{i}=Q_{f}=-V_{i}^{2} B_{\mathrm{SVC}} .
$$

In order to model the UPFC, the conventional converters of the UPFC are replaced through voltage/current sources, which alter Jacobian elements based on active and reactive power injections in the buses. In this work SVC and TCSC are combined to make UPFC model using (8) and (9) to evade alterations in power flow and Jacobian structure.

3.1. Proposed Strategy/Problem Formulation. The UPFC placement is chosen as an optimization problem and an objective is given by the following expression:

$$
\begin{aligned}
& \text { minimize } \Phi(x, y), \\
& \text { subject to } g(x, y)=0, \\
& h(x, y) \leq 0
\end{aligned}
$$

$x$ is the set of dependent variables consisting of active and reactive power of slack bus, reactive power of generator bus, and real power loss. $y$ is the vector of independent variables comprising location for UPFC placement and their parameters.

The equality constraint is the set of nonlinear power flow equations, which is presented as follows:

$$
\begin{aligned}
& P(V, \delta)-P^{s p}=0, \text { for generator and load buses, } \\
& Q(V, \delta)-Q^{s p}=0, \text { for bus. }
\end{aligned}
$$

Inequality constraints are defined by the following expressions:

$$
\begin{aligned}
-100 \mathrm{MVAR} & \leq Q_{f} \leq+100 \mathrm{MVAR}, \\
-0.8 & \leq \gamma_{t \mathrm{csc}} \leq 0.2, \\
Q_{G i}^{\min } & \leq Q_{G i} \leq Q_{G i}^{\max }, \text { for generator buses, } \\
V_{i}^{\min } & \leq V_{i} \leq V_{i}^{\max }, \text { for load buses. }
\end{aligned}
$$

In this work, three different single objectives (cases) are chosen through UPFC placement as follows. 
Case 1. Real power loss $\left(P_{\text {loss }}\right)$

The real power loss $\left(P_{\text {loss }}\right)$ minimization is expressed as follows [1]:

$$
\operatorname{minimize} J_{1}(x, y)=P_{\text {loss }}=\sum_{k \in \mathfrak{I}} g_{i j}\left(\left|V_{i}\right|^{2}+\left|V_{j}\right|^{2}-2\left|V_{i}\right|\left|V_{j}\right| \cos \delta_{i j}\right) \text {. }
$$

Case 2. Voltage profile improvement

Total voltage deviation (TVD) is minimized to improve the bus voltage profile as per the following equation [1]:

$$
\operatorname{minimize} J_{2}(x, y)=\sum_{j \in \Phi}\left|V_{j}-1\right| \text {. }
$$

Case 3. Voltage stability enhancement

The objective is formed to enhance voltage stability by minimizing L-index as per the following equation [1]:

$$
\begin{aligned}
\operatorname{minimize} J_{3}(x, y) & =\sum_{j \in \Phi} L_{j}, \\
\text { where } L_{j} & =\left|1-\sum_{i=\Omega} F_{i j} \frac{V_{i}}{V_{j}}\right| .
\end{aligned}
$$

Values of $F_{i j}$ are obtained through bus admittance matrix.

3.2. Illustration of SAFA Variables. Table 1 gives the information about the SAFA variables. The first row of Table 1 represents the transmission line number for the placement of UPFC and the subsequent rows represent reactive power injection, $Q_{f}$, compensation factor, and parameters of firefly.

3.3. Fitness Function. The SAFA maximizes the fitness function of light intensity function in order to provide the optimal solution.

$$
\begin{aligned}
\text { Maximize } L I & =\frac{1}{1+\Psi}, \\
\text { where } \Psi & =w_{1} J(x, u)+w_{v} \sum_{i=1}^{\text {nload }} V_{d i}+w_{Q} \sum_{j=1}^{n g e n}\left|Q_{G i}-Q_{G i}^{\lim i t}\right|^{2} .
\end{aligned}
$$

\section{Simulation and Discussion}

The simulation is performed on MATLAB software to analyse feasibility of SAFA for three-single-objective optimization through UPFC placement in standard IEEE 14, 30, and 57 test systems. Figure 1 demonstrates the flow of SAFA approach for UPFC placement.

Step-by-step procedure of SAFA for UPFC placement.

Step 1: read the considered system data.

Step 2: initialize the firefly parameters such as random movement factor $(\alpha)$, attractiveness parameter $\left(\beta_{\min }\right)$,
TABLE 1: Firefly illustration for UPFC placement.

\begin{tabular}{lcclc}
\hline$L_{1}$ & $L_{2}$ & $L_{3}$ & $\ldots$ & $L_{n f}$ \\
$Q_{f}^{1}$ & $Q_{f}^{2}$ & $Q_{f}^{3}$ & $\ldots$ & $Q_{f}^{n f}$ \\
$\gamma_{t c}^{1}$ & $\gamma_{t c}^{2}$ & $\gamma_{t c}^{3}$ & $\ldots$ & $\gamma_{t c}^{n f}$ \\
$\alpha$ & $\beta_{\min }^{2}$ & $\gamma$ & & \\
\hline
\end{tabular}

absorption coefficient $(\gamma)$, number of fireflies, and maximum number of iteration.

Step 3: generate the initial population of fireflies and firefly position is initiated using (5).

Step 4: set iteration counter and run the simulation to calculate the brightness of all considered fireflies.

Step 5: firefly position is modified based on the brightness of firefly. The new position of firefly is obtained by using (6).

Step 6: obtain the firefly parameters from rth and sth firefly.

Step 7: place the UPFC devices according to the location and parameters available in the rth and sth fireflies.

Step 8: run the load flow and compute the performances and light intensity of rth and sth fireflies.

Step 9: the firefly with highest light intensity in the population is the optimal solution.

Initially the SAFA approach is run considering diverse number of UPFCs for $P_{\text {loss }}$ minimization to select the number of UPFC for placement; besides, the solutions are presented in Table 2. It is possible to observe from Table 2 that the $P_{\text {loss }}$ reduced significantly from $13.2663 \mathrm{MW}$ to 13.2112 MW after three UPFCs are placed in 14 bus system. Likewise, $P_{\text {loss }}$ reduction is $17.1600 \mathrm{MW}$ from $17.5028 \mathrm{MW}$ when four UPFCs are placed in IEEE 30 bus system. Also, in the IEEE 57 bus system, $P_{\text {loss }}$ is reduced from $27.2233 \mathrm{MW}$ to 26.3094 MW while choosing five UPFCs for placement. If any other numbers of UPFC are chosen, the $P_{\text {loss }}$ reduction is insignificant; henceforth, three, four, and five UPFCs are chosen for 14, 30, and 57 bus systems, respectively, for the other two cases too.

Tables 3-5 provide information about the performances gained through simulations like $P_{\text {loss}}$, TVD, Maximum Voltage Stability Index (MVSI), and voltage magnitudes limits for all three cases of before and multiple UPFC placement of IEEE 14, 30, and 57 bus systems. It is possible to observe from Case 1 of Table 3 that the $P_{\text {loss }}$ is reduced significantly in 14 bus system from $13.2663 \mathrm{MW}$ to 13.2112 MW through SAFA, whereas HBA and BFA decrease to $13.2220 \mathrm{MW}$ and 13.2369 MW, respectively, when three UPFCs are placed. Likewise, in 30 bus system (Table 4), $P_{\text {loss }}$ decreased considerably from $17.5028 \mathrm{MW}$ to 17.1600 MW via SAFA, though HBA and BFA decreased to 17.1893 and 17.1916, respectively, when four UPFCs are placed. Similarly in IEEE 57 bus system (Table 5), $P_{\text {loss }}$ is reduced from $26.2233 \mathrm{MW}$ to $26.3094 \mathrm{MW}$ by SAFA, whereas HBA and BFA reduces to $27.0199 \mathrm{MW}$ and 27.0701 MW, respectively, when five UPFCs are considered. Moreover, all three algorithms provide the solution of bus 


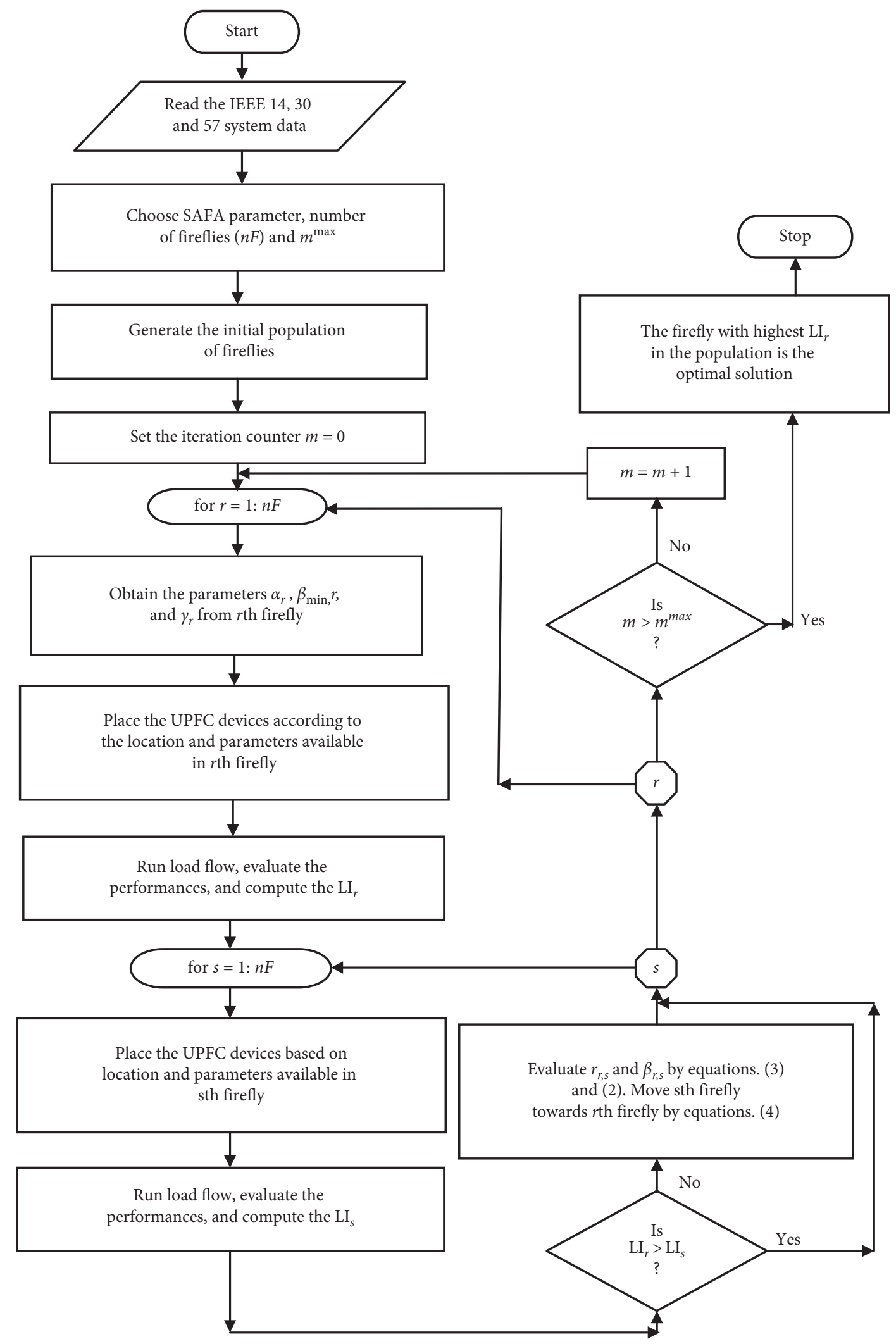

FIGURE 1: Flow of the SAFA for UPFC placement.

voltages to rest within the limits because voltage constraints are included in improved objective function. Since $P_{\text {loss }}$ reduction is an objective, the TVD rises and MVSI reduces while minimizing $P_{\text {loss }}$. The solutions clearly reveal that $P_{\text {loss }}$ is reduced significantly through optimal placement of UPFC by SAFA. 
TABLE 2: $P_{\text {loss }}$ reduction for diverse number of UPFC placement.

\begin{tabular}{lrr}
\hline System & UPFC no. & $P_{\text {loss }}$ \\
\hline \multirow{3}{*}{ IEEE 14} & 0 & 13.3663 \\
& 2 & 13.2365 \\
& 3 & 13.2112 \\
\hline & 4 & 13.2099 \\
IEEE 30 & 0 & 17.5028 \\
& 2 & 17.2321 \\
& 4 & 17.1600 \\
& 5 & 17.1470 \\
\hline IEEE 57 & 0 & 27.2233 \\
& 3 & 27.0701 \\
& 4 & 26.6395 \\
& 5 & 26.3094 \\
& 6 & 26.2842 \\
\hline
\end{tabular}

TABle 3: Performance solutions of the IEEE 14 bus system.

\begin{tabular}{lccccc}
\hline & Method & $P_{\text {loss }(M W)}$ & TVD & MVSI & $V^{\text {low }} / V^{\text {high }}(p, u)$ \\
\hline Before UPFC placement & & 13.3663 & 0.3822 & 0.0751 & $1.014 / 1.057$ \\
\hline \multirow{2}{*}{ Case 1} & SAFA & 13.2112 & 0.5629 & 0.0750 & $1.005 / 1.045$ \\
& HBA & 13.2220 & 0.4679 & 0.0651 & $1.009 / 1.040$ \\
\hline \multirow{3}{*}{ Case 2} & BFA & 13.2369 & 0.5255 & 0.0620 & $0.990 / 1.041$ \\
& SAFA & 15.7226 & 0.0603 & 0.0934 & $0.996 / 1.024$ \\
& HBA & 15.7233 & 0.0657 & 0.0950 & $0.991 / 1.023$ \\
Case 3 & BFA & 15.5517 & 0.0694 & 0.1005 & $0.994 / 1.028$ \\
& SAFA & 13.3066 & 0.4956 & 0.0488 & $1.016 / 1.073$ \\
& HBA & 13.4155 & 0.4764 & 0.0512 & $1.019 / 1.069$ \\
& BFA & 13.2930 & 0.4692 & 0.0538 & $1.023 / 1.068$ \\
\hline
\end{tabular}

Table 4: Performance solutions of IEEE 30 bus system.

\begin{tabular}{lccccc}
\hline & Method & $P_{\text {loss }}(\mathrm{MW})$ & TVD & MVSI & $V^{\text {low }} / V^{\text {high }}(p, u)$ \\
\hline Before UPFC placement & & 17.5028 & 0.4562 & 0.1420 & $0.989 / 1.082$ \\
\hline \multirow{2}{*}{ Case 1} & SAFA & 17.1600 & 0.9984 & 0.1211 & $1.009 / 1.040$ \\
& HBA & 17.1893 & 0.8373 & 0.1323 & $0.993 / 1.050$ \\
\hline \multirow{3}{*}{ Case 2} & BFA & 17.1916 & 1.0762 & 0.1237 & $0.952 / 1.048$ \\
& SAFA & 17.8501 & 0.1640 & 0.1475 & $0.985 / 1.026$ \\
& HBA & 18.0404 & 0.1871 & 0.1464 & $0.983 / 1.029$ \\
Case 3 & BFA & 17.7850 & 0.1974 & 0.1507 & $0.976 / 1.031$ \\
& SAFA & 18.4370 & 1.3456 & 0.0772 & $1.021 / 1.067$ \\
& HBA & 18.4987 & 1.2669 & 0.0832 & $1.014 / 1.117$ \\
\hline
\end{tabular}

TABle 5: Performance solutions of IEEE 57 bus system.

\begin{tabular}{|c|c|c|c|c|c|}
\hline & Method & $P_{\text {loss }}(\mathrm{MW})$ & TVD & MVSI & $V^{\text {low }} / V^{\text {high }}(p, u)$ \\
\hline Before UPFC placement & & 27.2233 & 1.2195 & 0.2914 & $0.936 / 1.061$ \\
\hline \multirow{3}{*}{ Case 1} & SAFA & 26.3094 & 0.9932 & 0.2644 & $0.960 / 1.059$ \\
\hline & HBA & 27.0199 & 1.1651 & 0.2845 & $0.952 / 1.048$ \\
\hline & BFA & 27.0701 & 1.0981 & 0.2705 & $0.950 / 1.051$ \\
\hline \multirow{3}{*}{ Case 2} & SAFA & 28.5457 & 0.8194 & 0.2716 & $0.958 / 1.050$ \\
\hline & HBA & 27.8055 & 0.9753 & 0.2739 & $0.961 / 1.049$ \\
\hline & BFA & 27.3661 & 0.9854 & 0.2817 & $0.957 / 1.051$ \\
\hline \multirow{3}{*}{ Case 3} & SAFA & 27.5225 & 1.3687 & 0.2233 & $0.970 / 1.058$ \\
\hline & HBA & 27.9907 & 1.0686 & 0.2483 & $0.958 / 1.057$ \\
\hline & BFA & 27.1042 & 1.0333 & 0.2683 & $0.954 / 1.054$ \\
\hline
\end{tabular}


In Case 2, an objective is chosen for the improvement of bus voltage profile by reducing total voltage deviation (TVD). It is possible to notice from Case 2 of Table 3 that TVD in 14 bus system reduced drastically from 0.3822 to 0.0603 by SAFA, whereas HBA and BFA decreased to 0.0657 and 0.0694 , respectively. Likewise, TVD decreased dramatically from 0.4562 to 0.1640 via SAFA in 30 bus system (Table 4); however, HBA and BFA decreased to 0.1871 and 0.1974 , respectively. In addition, TVD in 57 bus system reduced significantly from 1.2195 to 0.8194 by SAFA (Table 5), while HBA and BFA dropped off TVD to 0.9753 and 0.9854, respectively. In addition to this it can be seen from Case 2 of Tables 3-5 that all three algorithms provide solution of load bus voltage magnitudes to be nearer to one per unit as the chosen objective is voltage profile improvement. Thus, the solutions reveal that SAFA selects the best positions for UPFC placement with suitable parameters to improve VP more than HBA and BFA approaches.

The objective chosen in Case 3 is the enhancement of voltage stability (VS) by minimizing MVSI. It is possible to notice from Case 3 of Table 3 that MVSI in 14 systems is reduced substantially from 0.0751 to 0.0488 by SAFA, while $\mathrm{HBA}$ and BFA lessen to 0.0512 and 0.0538 , respectively. Likewise, in 30 bus system (Table 4), MVSI considerable reduction is 0.07772 from 0.1420 by SAFA; however, HBA and BFA decrease to 0.0832 and 0.0844 , respectively. Similarly, in 57 bus system (Table 5), MVSI is reduced significantly from 0.2914 to 0.2233 by SAFA, whereas HBA and BFA reduce MVSI to 0.2483 and 0.2683 , respectively. In addition to this, it is possible to notice from Case 3 in Tables 2-5 that voltage magnitudes are resting within the range offered by algorithms. Since $P_{\text {loss }}$ and TVD minimizations are not considered as objective in this case, $P_{\text {loss }}$ and TVD are higher in three test systems. Thus, the solutions reveal that SAFA selects best positions for UPFC placement with suitable parameters to enhance VS more than HBA and BFA approaches.

Figures 2-4 demonstrate the percentage of $P_{\text {loss }}$ savings rendered by optimization algorithms after UPFCs placement in 14, 30, and 57 bus systems, respectively. SAFA renders power loss saving as $1.16 \%$, whereas HBA and BFA offer $1.08 \%$ and $0.97 \%$, respectively, in 14 bus system. Similarly, in 30 bus system, $P_{\text {loss }}$ savings are $1.96 \%, 1.79 \%$, and $1.78 \%$ by $\mathrm{SAFA}, \mathrm{HBA}$, and BFA, respectively. Likewise, in 57 bus system $P_{\text {loss }}$ savings are $3.35 \%, 0.75 \%$, and $0.56 \%$ by SAFA, $\mathrm{HBA}$, and BFA, respectively. Figures 2-4 demonstrate clearly that SAFA approach offers higher power loss savings than HBA and BFA approaches.

Figures 5-7 illustrate the percentage of voltage profile (VP) improvement rendered by optimization algorithms after UPFCs placement in three test systems. In 14 bus system SAFA renders VP improvement as $84.22 \%$, whereas HBA and BFA offer $82.81 \%$ and $81.84 \%$, respectively. Similarly, in 30 bus system, VP improvements bestowed by SAFA, HBA, and BFA are 64.05\%, 58.99\%, and 56.73\%, respectively. Likewise, in 57 bus system VP improvement offered by SAFA, HBA, and BFA is $32.81 \%, 20.02 \%$, and $19.2 \%$, respectively. It can be seen from Figures 5-8 that the SAFA offers higher VP improvement than other techniques.

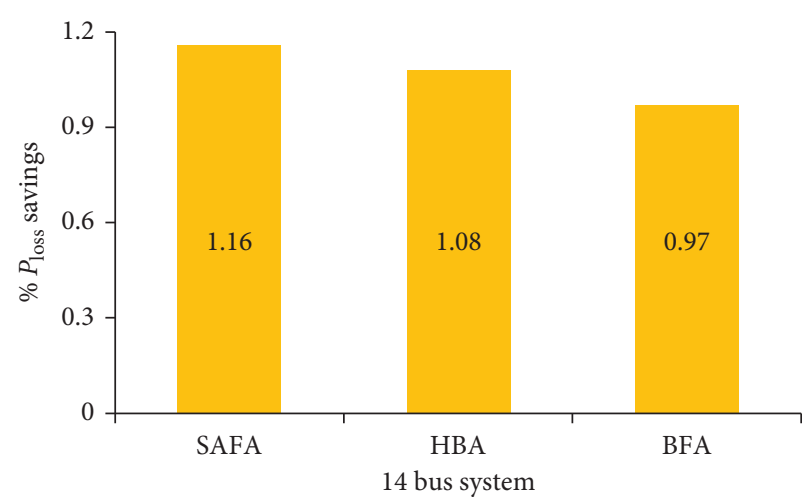

FIgURe 2: Comparison of $\% P_{\text {loss }}$ savings after UPFC placement of IEEE14 bus system.

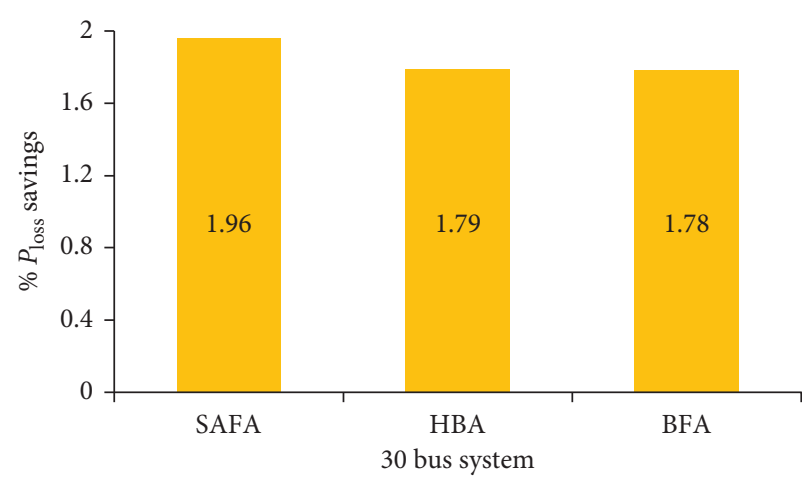

Figure 3: Comparison of $\% P_{\text {loss }}$ savings after UPFC placement of IEEE 30 bus system.

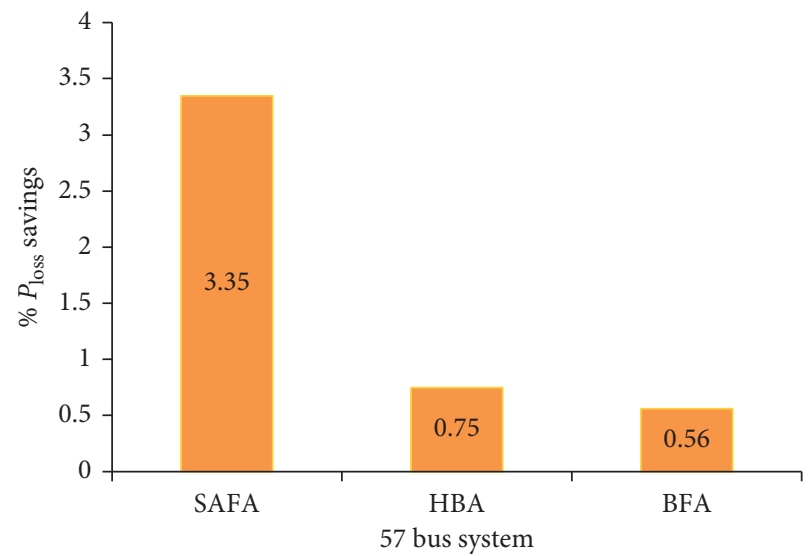

FIgURE 4: Comparison of $\% P_{\text {loss }}$ savings after UPFC placement of IEEE 57 bus system.

Figures 8-10 indicate the percentage of VS enhancement rendered by optimization algorithms after UPFCs placement in three test systems. In 14 bus system, SAFA renders a VS enhancement percentage of $35.01 \%$, whereas HBA and BFA offer $31.82 \%$ and $28.36 \%$, respectively. Similarly, in 30 bus system percentage VS enhancements are $45.63 \%, 41.41 \%$, and $40.46 \%$ by SAFA, HBA, and BFA, respectively. Likewise, in 57 bus system SAFA offers VS enhancement percentage of $23.36 \%$, while $\mathrm{HBA}$ and BFA present $14.79 \%$ and $7.93 \%$, 


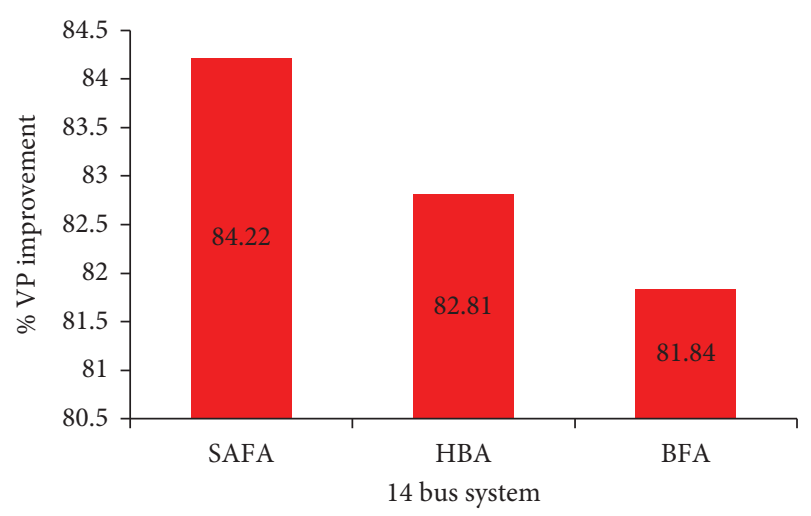

FIGURE 5: \% VP improvement comparison after UPFC placement of IEEE14 bus system.

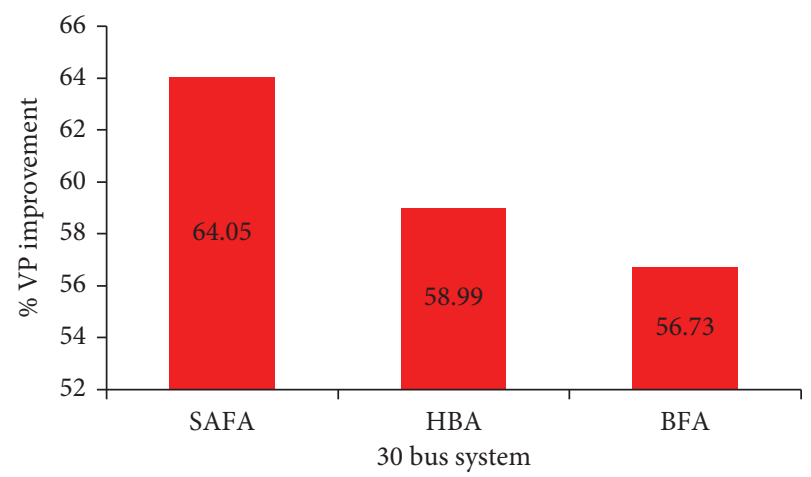

FIGURE 6: \% VP improvement comparison after UPFC placement of IEEE 30 bus system.

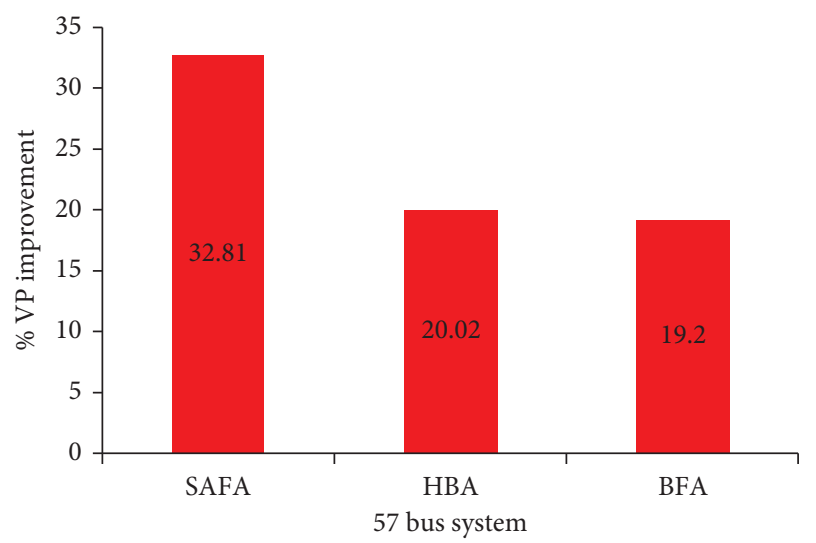

FIgURE 7: \% VP improvement comparison after UPFC placement of IEEE 57 bus system.

respectively. It is possible to see from Figures 8-10 that SAFA offers higher VS enhancement percentage than other approaches.

Load bus voltages of IEEE 14, 30, and 30 bus systems attained through SAFA for considering all the three cases before and after UPFC placement are presented in Figures 11-13, respectively. It should be noted from the

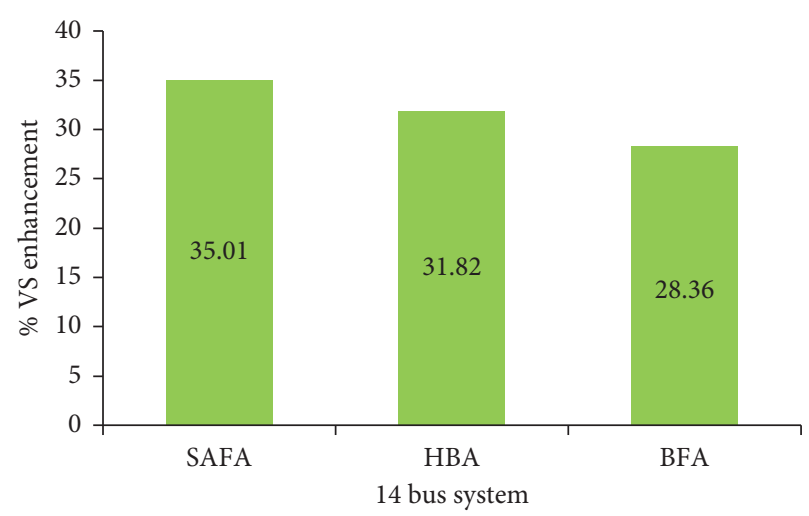

FIGURE 8: \% VS enhancement comparison after UPFC placement of IEEE14 bus system.

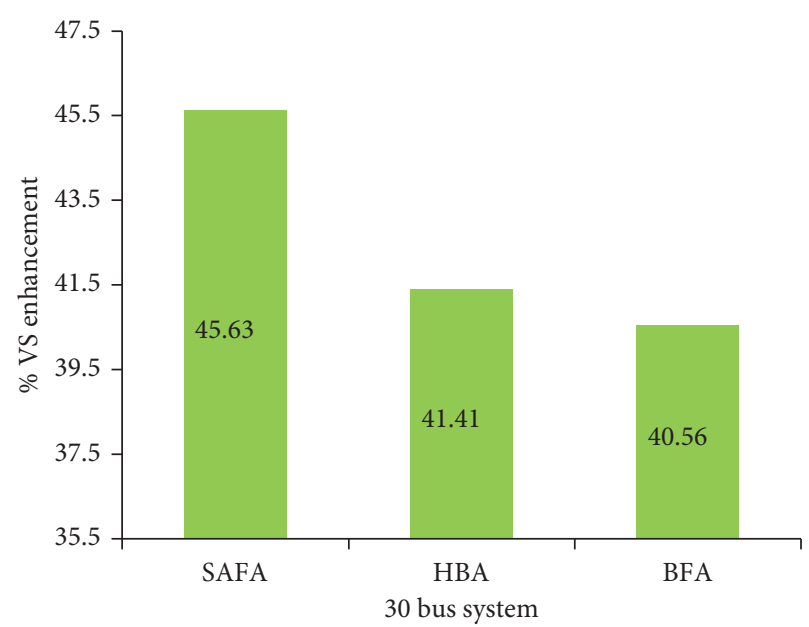

FIGURE 9: \% VS enhancement comparison after UPFC placement of 30 bus system.

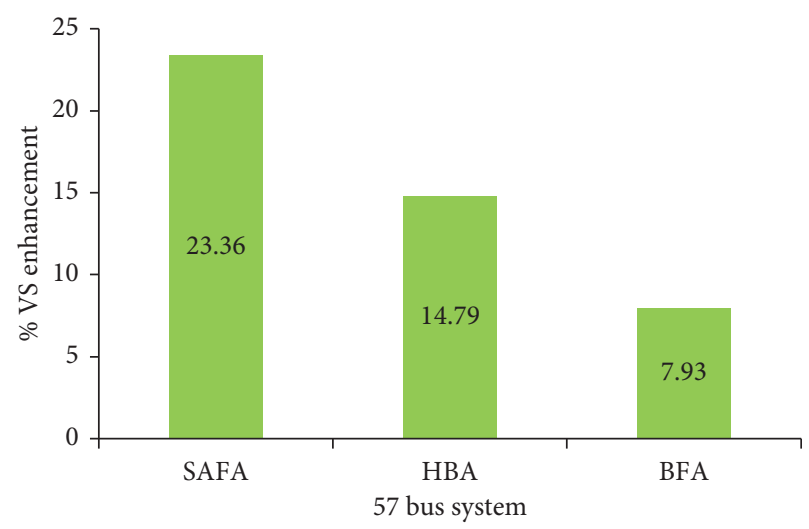

FIGURE 10: \% VS enhancement comparison after UPFC placement of 30 bus system.

graphs that curiously all the load bus voltage magnitudes are resting within the range between 0.95 and 1.1 p.u. for all the three cases of IEEE 14, 30, and 57 bus systems.

Figures 14-16 illustrate the convergence characteristic bestowed by SAFA for Case 1 of 14, 30, and 57 bus systems. It 


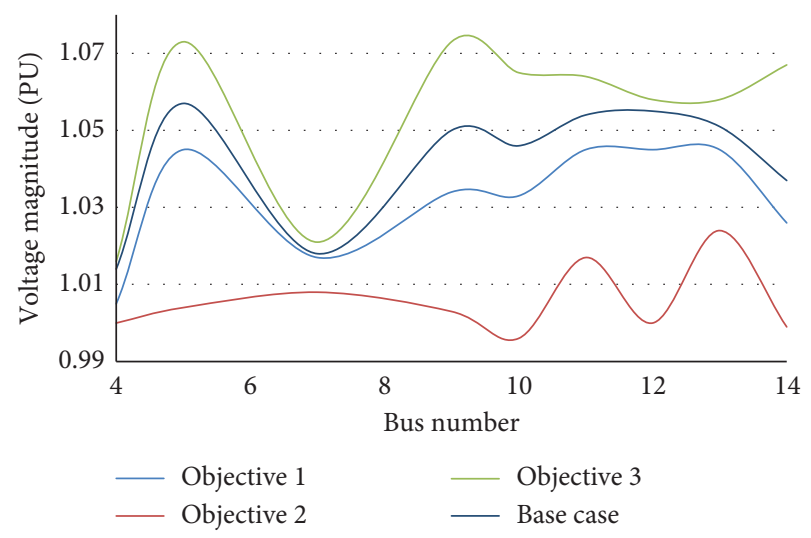

FIGURE 11: IEEE 14 bus system voltage magnitudes before and after UPFC placement.

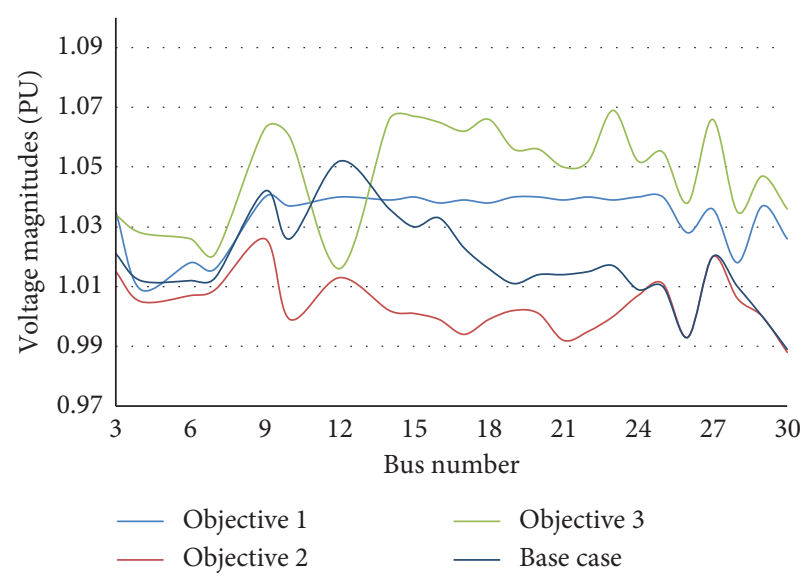

FIGURE 12: IEEE 30 bus system voltage magnitudes before and after UPFC placement.

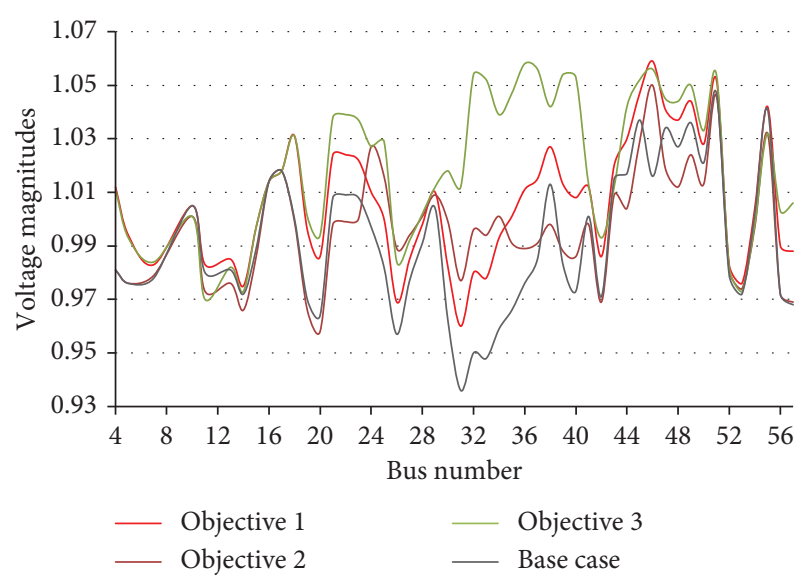

FIGURE 13: IEEE 14 bus system voltage magnitudes before and after UPFC placement.

can be seen from the figures that SAFA takes only 40 iterations to converge the optimal solution for both test systems. Moreover, the SAFA shows a stable and quick convergence with a global optimal solution for UPFC placement. In summary of the above discussions, SAFA

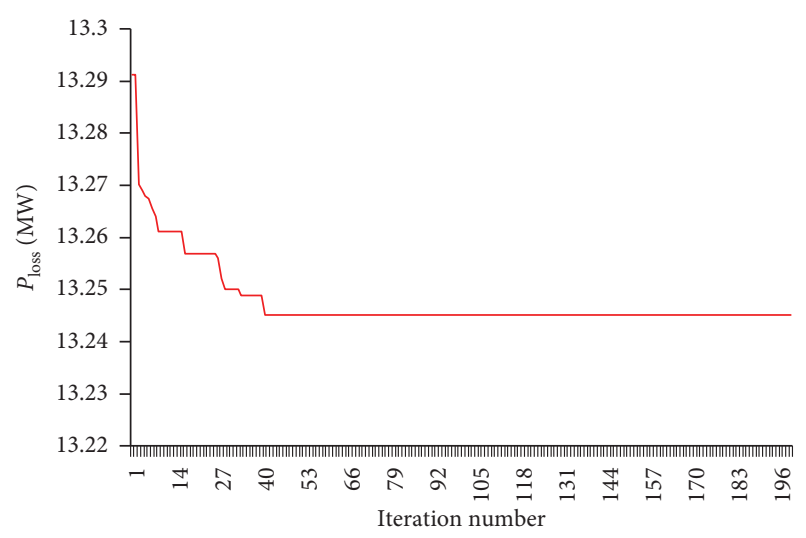

Figure 14: Convergence characteristic of 14 bus system.

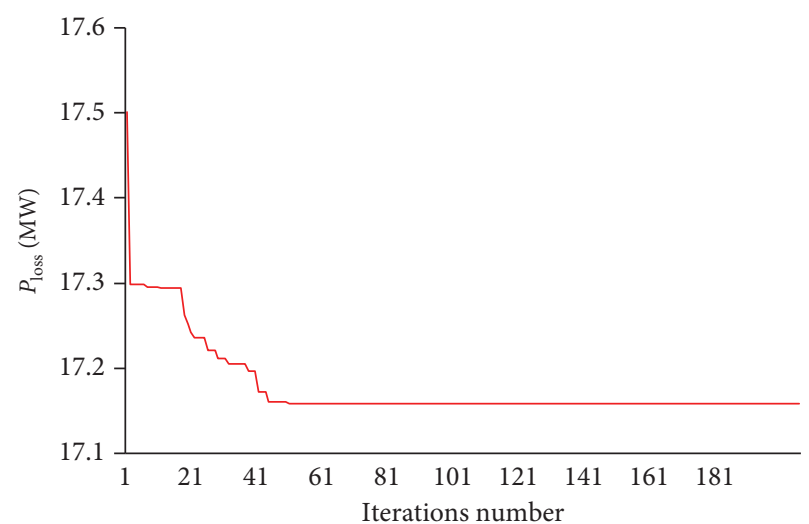

FIGURE 15: Convergence characteristic of 30 bus system.

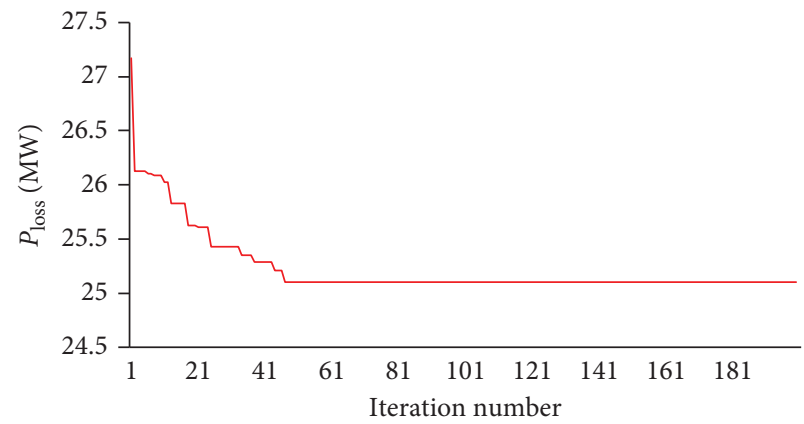

FIGURE 16: Convergence characteristic of 57 bus system.

identifies the best positions with appropriate parameters for UPFC placements to minimize $P_{\text {loss }}$, improve VP, and enhance VS of the existing system.

Tables 6-8 show information about the line locations and parameters for UPFC placement offered by SAFA. Table 9 provides information about control variables used for SAFA. One line diagram of IEEE 14, 30, and 57 test systems are shown in Figures 17-19.

It is very clear from the above discussions that the proposed SAFA-based strategy is able to reduce the loss to the lowest possible value than those of other strategies. In addition the self-adaptive nature of the algorithm avoids 
TABLE 6: UPFC location and parameter obtained by SAFA of 14 bus system.

\begin{tabular}{lcccc}
\hline & UPFC no. & 1 & 2 & 3 \\
\hline \multirow{3}{*}{ Case 1} & Line number & 9 & 20 & 17 \\
& Injected VAR & 9.992 & 7.854 & 12.696 \\
Case 2 & Compensation factor & -0.448 & -0.191 & -0.800 \\
& Line number & 15 & 18 & 19 \\
& Injected VAR & -50.000 & -18.677 & -32.519 \\
Case 3 & Compensation factor & -0.270 & -0.582 & 15 \\
& Line number & 9 & 13.386 & 31.955 \\
\hline
\end{tabular}

TABLE 7: UPFC location and parameter obtained by SAFA of 30 bus system.

\begin{tabular}{|c|c|c|c|c|c|}
\hline & UPFC no. & 1 & 2 & 3 & 4 \\
\hline \multirow{3}{*}{ Case 1} & Line number & 24 & 4 & 29 & 37 \\
\hline & Injected VAR & 7.043 & 21.718 & 17.280 & 7.661 \\
\hline & Compensation factor & -0.398 & -0.555 & 0.101 & -0.130 \\
\hline \multirow{3}{*}{ Case 2} & Line number & 24 & 33 & 28 & 17 \\
\hline & Injected VAR & 12.341 & 16.716 & -27.11 & -50.00 \\
\hline & Compensation factor & -0.310 & -0.552 & 0.099 & -0.212 \\
\hline \multirow{3}{*}{ Case 3} & Line number & 41 & 12 & 17 & 36 \\
\hline & Injected VAR & -38.60 & 34.941 & 82.140 & 45.825 \\
\hline & Compensation factor & -0.420 & -0.797 & -0.049 & -0.800 \\
\hline
\end{tabular}

TABLE 8: UPFC location and parameter obtained by SAFA of 57 bus system.

\begin{tabular}{lcccccc}
\hline & UPFC no. & 1 & 2 & 3 & 4 & 5 \\
\hline \multirow{3}{*}{ Case 1} & Line number & 52 & 4 & 49 & 61 & -50 \\
& Injected VAR & 12.820 & 57.122 & 5.04 & -5.485 & -15.409 \\
& Compensation factor & -0.396 & -0.328 & -0.617 & -0.425 & -0.512 \\
\hline \multirow{3}{*}{ Case 2 } & Line number & 38 & 79 & 37 & 47 & 46 \\
& Injected VAR & 16.761 & -49.160 & 5.040 & 16.675 & 5.488 \\
& Compensation factor & -0.334 & -0.406 & -0.275 & -0.169 \\
\hline \multirow{2}{*}{ Case 3 } & Line number & 46 & 49 & 60 & 71 \\
& Injected VAR & 0.987 & 52.644 & -37.150 & 50.309 & -19.690 \\
& Compensation factor & -0.774 & -0.487 & -0.750 & -0.050 & -0.523 \\
\hline
\end{tabular}

TABLE 9: Control variables.

\begin{tabular}{lccc}
\hline & & Minimum & Maximum \\
\hline \multirow{2}{*}{ Power system variables } & Voltage magnitude $(\mathrm{PM})$ & 0.95 & 1.1 \\
& $Q_{\text {SVC }}(\mathrm{MVR})$ & -100 & 100 \\
\hline \multirow{3}{*}{ Self-adaptive parameters } & Random movement factor $(\alpha)$ & 0 & 0.5 \\
& Attractiveness parameter $\left(\beta_{\min }\right)$ & 0.2 & 0 \\
\hline & Absorption coefficient $(\gamma)$ & 0 & 1 \\
\hline
\end{tabular}




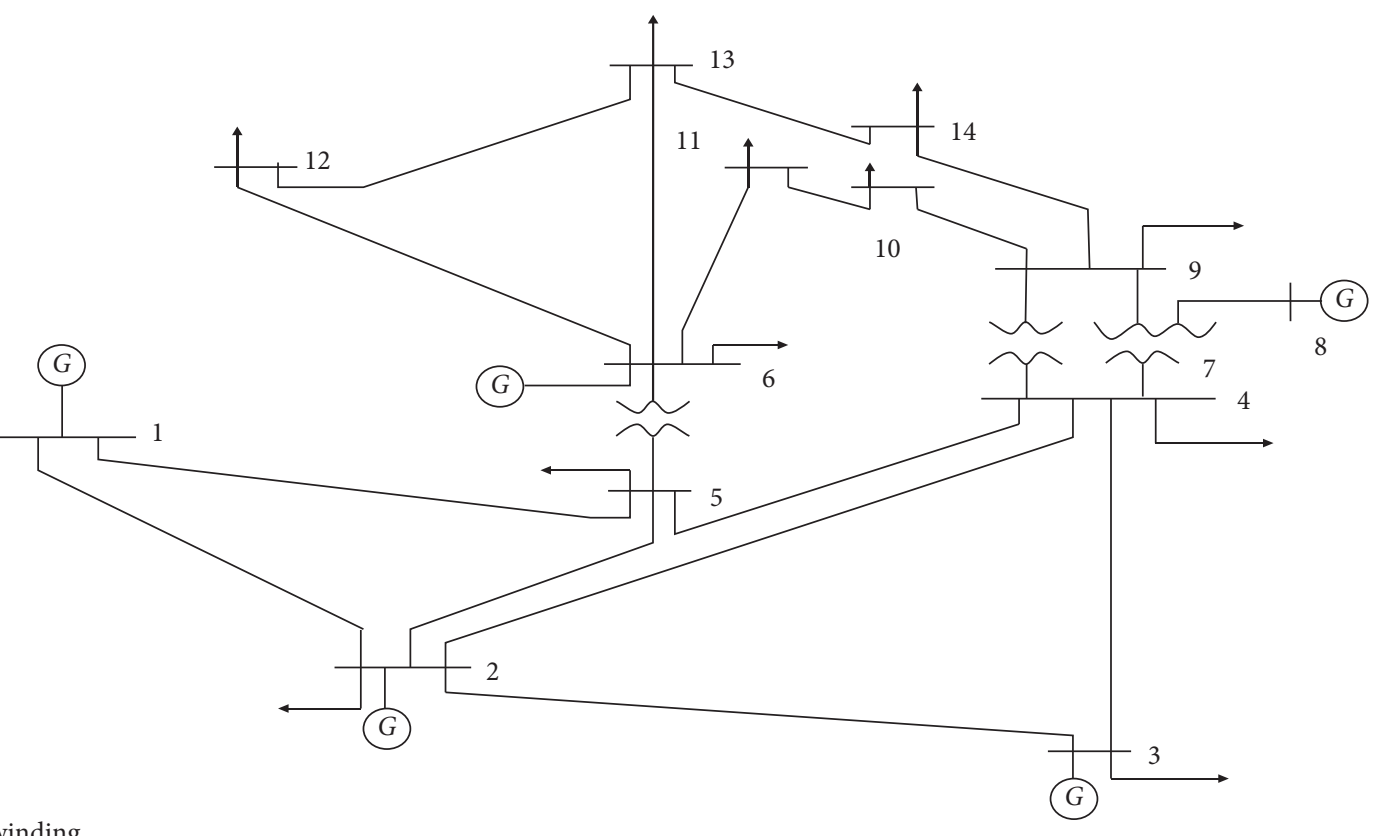

Three winding transformer equivalent

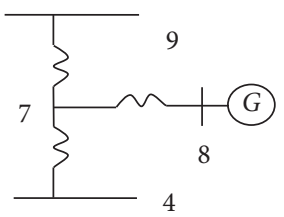

(G) -Generators

$\longrightarrow$-Loads

Figure 17: One line diagram of IEEE 14 bus system.

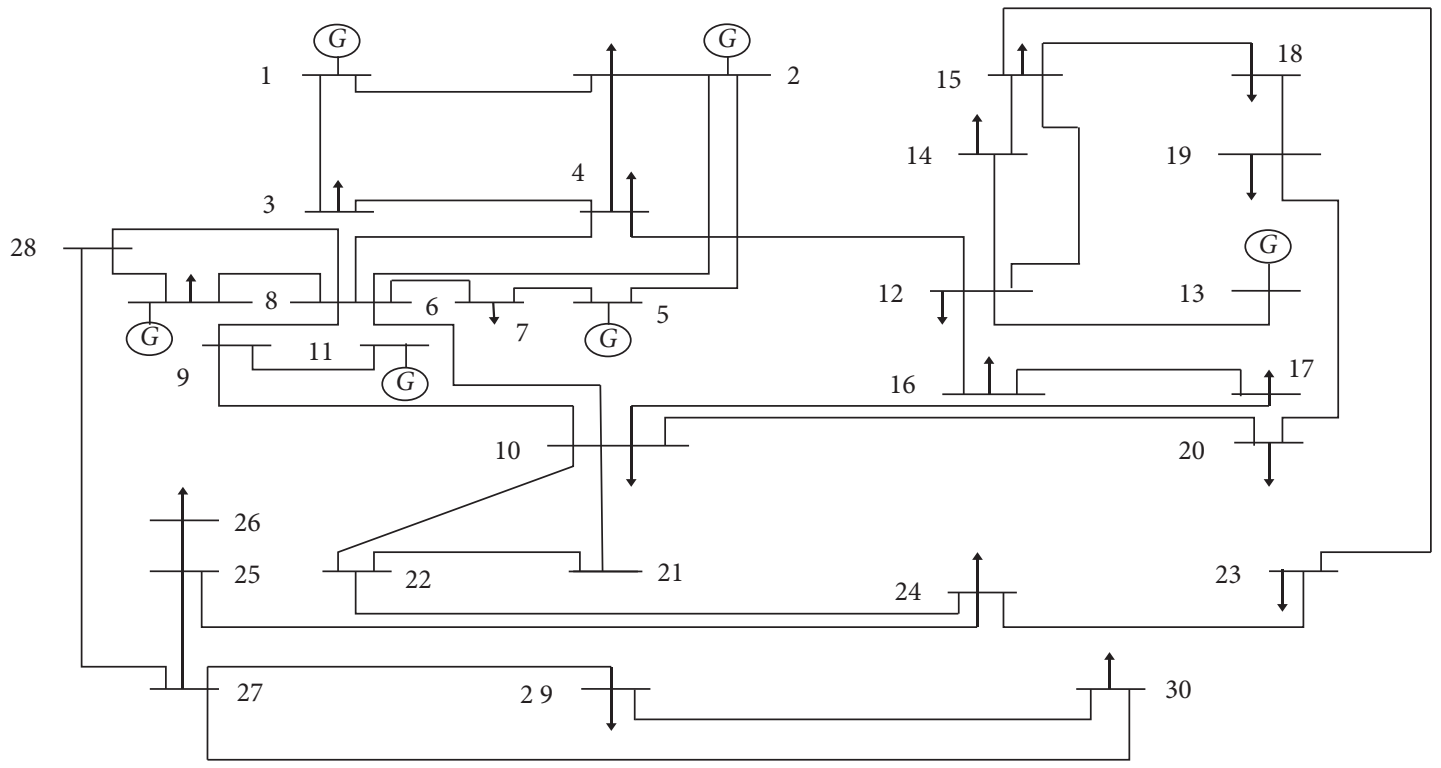

(G) Generators

$\rightarrow$ Loads

FIgURE 18: One line diagram of IEEE 30 bus system. 


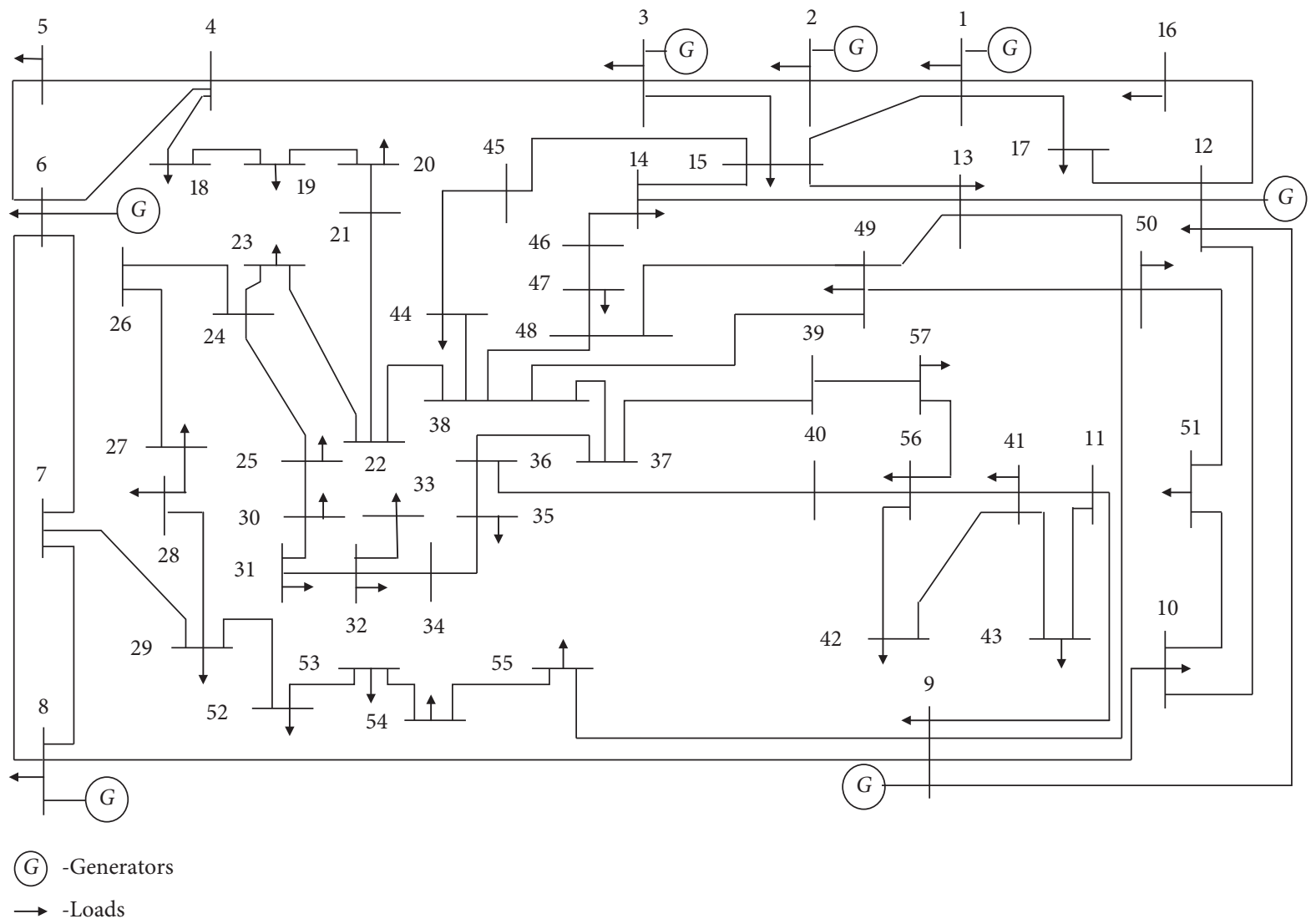

Figure 19: One line diagram of IEEE 57 bus system.

repeated runs for fixing the optimal FA parameters through a trial-and-error procedure and provides the best possible parameters values.

\section{Conclusion}

In this work, self-adaptive firefly algorithm (SAFA) is employed for optimal placement of UPFC in transmission network. SAFA seeks the optimal positions and parameters of UPFC for their installation in IEEE 14, 30, and 57 bus systems. The simulations are performed on MATLAB software for three single objectives (cases) of real power loss minimization, voltage profile improvement, and voltage stability enhancement. The solutions are presented in terms of $\mathrm{P}_{\text {loss }}$, TVD, MVSI, and lower and higher voltage magnitudes for three cases of three test systems with comparative results in Section 4. SAFA offers less computational effort, avoiding the suboptimal solution and convergence enhancement. It is evidenced from the solutions that SAFA renders healthier performance than HBA and BFA for UPFCs placement with appropriate parameters; thereby, power system can be operated in reliable and secured manner. The proposed SAFA approach owing to its simple computations has been able to provide practical implementation of any size of power system.
This study opens several lines for future work. Analysis of the existing tradeoffs and evaluation of other metrics are some of the future works of this research. This work can be extended by following the same fashion for large-scale bus systems. Other performance parameters can also be analysed in future works. Various improvements of the proposed SAFA for engineering applications can also be investigated and compared in detail in the future.

\section{Nomenclature}

BSVC: $\quad$ Susceptance of SVC

$g_{i j}: \quad j$ conductance of line between buses $i$ and $j$

$g(x, y): \quad$ Equality constraints

$h(x, y): \quad$ Inequality constraints

$\mathrm{LI}_{r}$ : $\quad$ Light intensity of the $r$ th firefly

nload: $\quad$ Number of load buses

ngen: Number of generator buses

nd: $\quad$ Number of decision variables

$P_{\text {loss: }}: \quad$ Net transmission loss

$P^{s P}: \quad$ Specified real power at PV and PQ buses

$P(V, \delta): \quad$ Set of real power expressions at $\mathrm{PV}$ and $\mathrm{PQ}$ buses

$Q_{G i}^{\min }, \quad$ Minimum and maximum reactive power

$Q_{G i}^{\max }: \quad$ generation by the $i$ th generator, respectively

$Q_{G i}: \quad$ Reactive power generation at ith generator 
$Q^{s p}: \quad$ Specified reactive powers at PQ buses

$Q(V, \delta)$ : Set of reactive power expressions at PQ buses

$Q_{f}: \quad$ Reactive power supplied by SVC

$r_{r, s}: \quad$ Cartesian distance between fireflies $r$ and $s$

$V_{i}^{\min }$,

$V_{i}^{\max }$ : $\quad$ Minimum and maximum $i$ th load bus voltages

$x_{i j}$ : $\quad$ Transmission line reactance between buses $i$ and $j$

$X_{t c}: \quad$ Reactance of TCSC

Greek Symbols

$\delta_{i j}$ : Voltage angle between buses $i$ and $j$

$\mathfrak{I}$ : A set of generator and load buses

$\Psi$ : A set of load buses

$\alpha$ : Random movement factor

$\beta_{r, s}:$ Attractiveness parameter between two fireflies

$\gamma_{r}:$ Absorption coefficient

$\gamma_{t c}$ : TCSC line compensation factor.

\section{Data Availability}

The data used to support the findings of this study are available from the corresponding author upon request.

\section{Consent}

Informed consent was obtained from all individual participants included in the study.

\section{Conflicts of Interest}

The authors declare that they have no conflicts of interest.

\section{Authors' Contributions}

All authors equally contributed to the study conception and design and implementation of the research, analysis and interpretation of results, and manuscript preparation.

\section{References}

[1] S. Ranganathan, M. Surya Kalavathi, and C. Asir Rajan, "Selfadaptive firefly algorithm based multi-objectives for multitype FACTS placement," IET Generation, Transmission \& Distribution, vol. 10, no. 11, pp. 2576-2584, 2016.

[2] N. G. Hingorani and L. Gyugyi, Understanding FACTS: Concepts and Technology of Flexible AC Transmission Systems, Wiley, IEEE Press, Hoboken, NJ, USA, 1999.

[3] R. M. Mathur and R. K. Varma, Thyristor-based FACTS Controllers for Electrical Transmission Systems, IEEE Press, Piscataway, NJ, USA, 2002.

[4] R. Mohamed Idris, A. Khairuddin, and W. Mustafa, "Optimal allocation of FACTS devices for ATC enhancement using Bees algorithm," World Academy of Science Engineering and Technology, vol. 30, pp. 313-320, 2009.

[5] I. Ghamgeen, Y. S. Rashed, and H. I. Shaheen, "Optimal location and parameter setting of TCSC for loss minimization based on differential evolution and genetic algorithm," Physics Procedia, vol. 33, pp. 1864-1878, 2012.

[6] C.-F. Lu, C.-H. Hsu, and C.-F. Juang, "Coordinated control of flexible AC transmission system devices using an evolutionary fuzzy lead-lag controller with advanced continuous ant colony optimization," IEEE Transactions on Power System, vol. 28, no. 1, pp. 385-392, 2012.

[7] B. Bhattacharyya and V. K. Gupta, "Application of DE \& PSO algorithm for the placement of FACTs devices for economic operation of a power system," WSEAS Transactions on Power System, vol. 7, no. 4, pp. 209-216, 2016.

[8] A. R. Jordehi, "Particle swarm optimisation (PSO) for allocation of FACTS devices in electric transmission systems: a review," Renewable and Sustainable Energy Reviews, vol. 52, pp. 1260-1267, 2015.

[9] T. Niknam, H. D. Mojarrad, H. Z. Meymand et al., "A new honey bee mating optimization algorithm for non-smooth economic dispatch," Energy, vol. 36, no. 2, pp. 896-908, 2011.

[10] M. Kumar and P. Renuga, "Application of UPFC for enhancement of voltage profile and minimization of losses using fast voltage stability index (FVSI)," Archives of Electrical Engineering, vol. 61, no. 2, pp. 239-250, 2012.

[11] K. R. Devabalaji, K. Ravi, and D. P. Kothari, "Optimal location and sizing of capacitor placement in radial distribution system using bacterial foraging optimization Algorithm," International Journal of Electrical Power \& Energy Systems, vol. 71, pp. 383-390, 2015.

[12] X. S. Yang, Nature-inspired Meta-Heuristic Algorithms, Luniver Press, Beckington, UK, 2nd edition, 2010.

[13] X. S. Yang, S. S. Hosseini, and A. H. Gandomi, "Firefly algorithm for solving non-convex economic dispatch problems with valve loading effect," Applied Soft Computing, vol. 12, no. 3, pp. 180-186, 2012.

[14] K. Chandrasekaran and S. P. Simon, "Network and reliability constrained unit commitment problem using binary real coded firefly algorithm," International Journal of Electrical Power \& Energy Systems, vol. 43, no. 1, pp. 921-932, 2012.

[15] R. Selvarasu, M. Surya Kalavathi, and C. C. Asir Rajan, "SVC placement for voltage constrained loss minimization using self-adaptive firefly algorithm," Archives of Electrical Engineering, vol. 62, no. 4, pp. 649-661, 2013.

[16] R. Selvarasu and M. Surya Kalavathi, "Optimal placement of UPFC voltage constrained loss minimization using selfadaptive firefly algorithm," International Review of Electrical Engineering, vol. 8, no. 4, pp. 1296-1301, 2013.

[17] R. Selvarasu and M. Surya Kalavathi, "TCSC placement for loss minimization using self-adaptive firefly algorithm," Journal of Engineering Science and Technology, vol. 10, no. 3, pp. 291-306, 2015.

[18] E. Barrios-Martínez and C. Ángeles-Camacho, "Technical comparison of FACTS controllers in parallel connection," Journal of Applied Research and Technology, vol. 15, no. 1, pp. 36-44, 2017.

[19] S. Raj and B. Bhattacharyya, "Optimal placement of TCSC and SVC for reactive power planning using whale optimization algorithm," Swarm and Evolutionary Computation, vol. 40, pp. 131-143, 2018.

[20] P. R. Sahu, P. K. Hota, and S. Panda, "Power system stability enhancement by fractional order multi input SSSC based controller employing whale optimization algorithm," Journal of Electrical System and Information Technology, vol. 5, pp. 326-336, 2018.

[21] R. Agrawal, S. K. Bharadwaj, and D. P. Kothari, "Population based evolutionary optimization techniques for optimal allocation and sizing of thyristor controlled series capacitor," Journal of Electrical Systems and Information Technology, vol. 5, no. 3, pp. 484-501, 2018.

[22] A. Sharma and S. K. Jain, "Gravitational search assisted algorithm for TCSC placement for congestion control in 
deregulated power system," Electric Power Systems Research, vol. 174, Article ID 105874, 2019.

[23] R. Kumar, R. Singh, and H. Ashfaq, "Stability enhancement of multi-machine power systems using ant colony optimizationbased static synchronous compensator," Computers \& Electrical Engineering, vol. 83, Article ID 106589, 2020.

[24] M. Ettappan, V. Vimala, S. Ramesh, and V. T. Kesavan, "Optimal reactive power dispatch for real power loss minimization and voltage stability enhancement using artificial bee colony algorithm," Microprocessors and Microsystems, vol. 76, Article ID 103085, 2020.

[25] F. M. Albatsh, S. Mekhilef, S. Ahmad, and H. Mokhlis, "Fuzzylogic-based UPFC and laboratory prototype validation for dynamic power flow control in transmission lines," IEEE Transactions on Industrial Electronics, vol. 64, no. 12, pp. 9538-9548, 2017.

[26] S. Ahmad, F. M. Albatsh, S. Mekhilef, and H. Mokhlis, "A placement method of fuzzy based unified power flow controller to enhance voltage stability margin," in Proceedings of the 16th European Conference on Power Electronics and Applications, pp. 1-10, Lappeenranta, Finland, August 2014.

[27] O. Mofid, S. Mobayen, and M. Khooban, "Sliding mode disturbance observer control based on adaptive synchronization in a class of fractional order chaotic systems," International Journal of Adaptive Control and Signal Processing, vol. 33, pp. 462-474, 2018.

[28] S. Mobayen, "Adaptive global terminal sliding mode control scheme with improved dynamic surface for uncertain nonlinear systems," International Journal of Control, Automation and Systems, vol. 16, no. 4, pp. 1692-1700, 2018.

[29] S. Mobayen and F. Tchier, "Robust global second-order sliding mode control with adaptive parameter-tuning law for perturbed dynamical systems," Transactions of the Institute of Measurement and Control, vol. 40, no. 9, pp. 2855-2867, 2018.

[30] O. Mofid and S. Mobayen, "Adaptive synchronization of fractional-order quadratic chaotic flows with nonhyperbolic equilibrium," Journal of Vibration and Control, vol. 24, pp. 4971-4987, 2017.

[31] S. Mobayen, "Adaptive global sliding mode control of underactuated systems using a super-twisting scheme: an experimental study," Journal of Vibration and Control, vol. 25, no. 16, pp. 2215-2224, 2019.

[32] S. Ben Warrad, O. Lungu, and S. Mobayen, "Full and reducedorder unknown input observer design for linear time-delay systems with multiple delays," Mathematical Problems in Engineering, vol. 2018, Article ID 1745734, 13 pages, 2018.

[33] A. Modiri and S. Mobayen, "Adaptive terminal sliding mode control scheme for synchronization of fractional-order uncertain chaotic systems," ISA Transactions, vol. 105, pp. 33-50, 2020.

[34] H. Karami, S. Mobayen, M. Lashkari, F. Bayat, and A. Chang, "LMI-observer-based stabilizer for chaotic systems in the existence of a nonlinear function and perturbation," Mathematics, vol. 9, no. 10, p. 1128, 2021. 